(2) Open Access Full Text Article

\title{
Application of reticulated platelets to transfusion management during autologous stem cell transplantation
}

This article was published in the following Dove Press journal:

OncoTargets and Therapy

25 January 2012

Number of times this article has been viewed

\author{
Sergio Parco \\ Fulvia Vascotto \\ Institute for Maternal and Child \\ Health - IRCCS Burlo Garofolo, \\ Trieste, Italy
}

Correspondence: Sergio Parco Institute for Maternal and Child Health - IRCCS Burlo Garofolo, Via dell'Istria 65/I, 34137 Trieste, Italy Tel +390403785332

Fax +390403785210

Email parco@burlo.trieste.it
Background: The immature (or reticulated) platelet fraction (IPF) is rich in nucleic acids, especially RNA, and can be used as a predictive factor for platelet recovery in platelet immunomediated consumption or in postchemotherapy myelosuppression. Our aim was to determine if transfusions with IPF-rich solutions, during autologous peripheral blood stem cell transplantation, reduce the occurrence of bleeding and hemorrhagic complications.

Patients and methods: Transfusions were administered to 40 children, affected with hematological pathologies, who underwent autologous peripheral hematopoietic progenitor cell transplantation. There were two groups of 20 patients, one group treated with IPF-poor and the other with IPF-rich solutions. In the two groups, the conditioning regimen was the same for the same pathology (hematological pathologies: 14 acute lymphoblastic leukemia; twelve acute myelocytic leukemia; four non-Hodgkin's lymphoma; two Hodgkin's lymphoma; eight solid tumors). A new automated analyzer was used to quantify the IPF: the XE2100 (Sysmex, Kobe, Japan) blood cell counter with upgraded software.

Results: The 20 patients who received solutions with a high percentage of IPF $(3 \%-9 \%$ of total number of infused platelets) required fewer transfusions than the 20 patients who received transfusions with a low percentage of IPF $(0 \%-1 \%$ of total number of infused platelets): 83 versus 129 (mean of number of transfusions 4.15 versus 6.45 ) and a significant difference was found between the two groups by using the Mann-Whitney test $(P<0.001)$. The prophylactic transfusions decreased from three to two per week. There was only one case of massive hemorrhage.

Conclusion: The use of IPF solutions reduces the number of transfusions and bleedings after peripheral blood stem cell transplantation in pediatric patients.

Keywords: children, reticulated platelet fraction, transfusion management, hemorrhage

\section{Introduction}

Immature (or reticulated) platelets (PLTs) contain more RNA than mature PLTs and their number in peripheral blood reflects the rate of thrombopoiesis. Immature PLTs are more active than nonreticulated PLTs because of their higher nucleic acid content and higher expression of P-selectin and glycoprotein. New automated, US Food and Drug Administration-approved methods have been developed to count immature PLTs. ${ }^{1-3}$ The immature PLT fraction (IPF) count is a useful index of thrombopoiesis, which increases when the IPF rises and decreases when the IPF declines.

The IPF count reflects peripheral PLT destruction that results from the suppression of bone marrow production and can be used as a predictive factor for PLT recovery 
Table I Data for immature platelet fraction-administered concentrates ( $A B O$ compatible)

\begin{tabular}{llll}
\hline & $\begin{array}{l}\text { Total } \\
\text { numbers }\end{array}$ & $\begin{array}{l}\text { Whole dose } \\
\left(3 \pm 0.2 \times 10^{\prime \prime}\right)\end{array}$ & $\begin{array}{l}\text { Half dose } \\
\left(1.5 \pm 0.2 \times 10^{\prime \prime}\right)\end{array}$ \\
\hline IPF-poor & 129 & 81 & 48 \\
IPF-rich & 83 & 52 & 31 \\
\hline
\end{tabular}

Abbreviation: $A B O$, blood groups $A, B, A B$, and $O$.

postchemotherapy myelosuppression or in PLT immunomediated consumption. IPF counts have been described as a better marker of PLT activity not only in thrombopoietic disorders, such as thrombotic thrombocytopenia purpura but also in various clinical conditions, such as hematopoietic stem cell transplantation, myelodysplasia, acute coronary syndrome, and in patients on hemodialysis. ${ }^{4-7}$

In this study, we tested the efficacy of transfusions in pediatric patients, who underwent autologous peripheral hematopoietic progenitor cell transplantation, with PLT concentrates (PCs) enriched with young and more active PLTs (IPF). We determined whether this treatment reduced the occurrence of massive or mucosal hemorrhage during the post-transplantation period.

The study design was to evaluate the relationship between two groups of transfusions, one with IPF-poor and the other with IPF-rich solutions stored for the same time and similarly administered in terms of transfusion frequency, and the development of hemorrhagic or transfusion-transmitted complications. ${ }^{8,9}$ We also aimed to verify the utility of a new automated hemoanalyzer to count the IPF in donors and in PCs and to study the outcome in patients.

\section{Materials and methods}

Over a 2-year period, two groups of 20 children (aged 5-18 years) received transfusions with either IPF-poor solutions or with IPF-rich solutions, during autologous peripheral blood stem cell (PBSC) transplantation, according to the EU procedures ${ }^{33}$ as reported in the manual for transfusions at our hospital. In the two groups, the conditioning regimen was the same for the same pathology (hematological pathologies: 14 acute lymphoblastic leukemia, twelve acute myelocytic leukemia (AML), four non-Hodgkin's lymphoma, two Hodgkin's lymphoma, eight solid tumors). Young patients were classified as follows: (1) stable and receiving prophylactic therapy, having a PLT count $<10,000 / \mu \mathrm{L}$; (2) having mucosal hemorrhage with a PLT count $<50,000 / \mu \mathrm{L}$; (3) exhibiting signs of active bleeding from insertion catheters with a PLT count between 50,000 and $100,000 / \mu \mathrm{L}$; (4) experiencing massive blood loss with a PLT count of $<50,000 / \mu \mathrm{L}$. Before entering this study an informed consent form was delivered to all patients (or their parents), which was approved by the Ethics Committee of the Hospital; only one patient did not return the consent form.

The IPF is donor dependent (range in human blood: $0.3 \%-$ $7.0 \%$ of total PLT). The blood donors in our study were selected into two groups, one with an IPF range of $0.3 \%-3.5 \%$, the other with a range of $3.6 \%-7.0 \%$. To quantify the reticulated PLTs, we used a new automated instrument, the XE-2100 (Sysmex, Kobe, Japan), with a modern routine, fully automated analyzer and upgraded software. ${ }^{10}$ The thrombelastograph (Medival, Padua, Italy) was implemented to aid in the treatment of possible coagulopathy. We used the Procleix Ultrio (Chiron Ltd, Emeryville, CA) test kit-based transcription-mediated amplification for nucleic acid amplification testing studies of serum samples from donors (human immunodeficiency virus, hepatitis $C$ virus, and hepatitis $B$ virus). Otherwise, a microenzyme-linked immunosorbent assay was used in parallel for routine serological screening of anti-human immunodeficiency virus, anti-hepatitis $\mathrm{C}$ virus and $\mathrm{HBsAg}$ antibodies (Roche, Milan, Italy). For the syphilis test we used a chemiluminescence method (Abbott, Milan, Italy).

The PLT apheresis procedures were performed using healthy volunteer donors according to European regulations. A blood cell separator (Haemonetics MCS Plus version C, Haemonetics Corp, Baintree, MA) was used, with multicomponent collection kits. After collecting standard PLT, the separator was adjusted to collect PLT cyclically. Cycle numbers and volumes were adjusted in the processor to collect an average of $3.0 \times 10^{11}( \pm 0.5)$ PLTs according to the donors' weight and height. Before the plasma reinfusion phase, PLTs

Table 2 Use of immature platelet fraction-rich solutions during post-cell transplant period in categories with platelet count $<10,000 / \mu \mathrm{L}$ (prophylactic therapy) and $<50,000 / \mu \mathrm{L}$ (mucosal hemorrhage)

\begin{tabular}{llllllllllllllllllllll}
\hline Patients & I & $\mathbf{2}$ & $\mathbf{3}$ & $\mathbf{4}$ & $\mathbf{5}$ & $\mathbf{6}$ & $\mathbf{7}$ & $\mathbf{8}$ & $\mathbf{9}$ & $\mathbf{1 0}$ & $\mathbf{I I}$ & $\mathbf{1 2}$ & $\mathbf{1 3}$ & $\mathbf{1 4}$ & $\mathbf{1 5}$ & $\mathbf{1 6}$ & $\mathbf{1 7}$ & $\mathbf{1 8}$ & $\mathbf{1 9}$ & $\mathbf{2 0}$ \\
\hline Number of transfusions & 4 & 4 & 4 & 4 & 6 & 4 & 4 & 4 & 4 & 4 & 4 & 5 & 4 & 4 & 4 & 4 & 4 & 4 & 4 & 4 \\
Massive hemorrhages & 0 & 0 & 0 & 0 & $\mathbf{1}$ & 0 & 0 & 0 & 0 & 0 & 0 & 0 & 0 & 0 & 0 & 0 & 0 & 0 & 0 & 0 \\
Mucosal hemorrhages & 0 & 0 & 0 & 0 & 0 & 0 & 0 & 0 & 0 & 0 & 0 & I & 0 & 0 & 0 & 0 & 0 & 0 & 0 & 0 \\
Number of infections & 0 & 0 & 0 & 0 & 0 & 0 & 0 & 0 & 0 & 0 & 0 & 0 & 0 & 0 & 0 & 0 & 0 & 0 & 0 & 0 \\
\hline
\end{tabular}


Table 3 Use of immature platelet fraction-poor solutions during post-cell transplant period in categories with platelet count $<$ 10,000/ $\mu \mathrm{L}$ (prophylactic therapy) and $<50,000 / \mu \mathrm{L}$ (mucosal hemorrhage)

\begin{tabular}{lllllllllllllllllllll}
\hline Patients & $\mathbf{1}$ & $\mathbf{2}$ & $\mathbf{3}$ & $\mathbf{4}$ & $\mathbf{5}$ & $\mathbf{6}$ & $\mathbf{7}$ & $\mathbf{8}$ & $\mathbf{9}$ & $\mathbf{1 0}$ & $\mathbf{1 1}$ & $\mathbf{1 2}$ & $\mathbf{1 3}$ & $\mathbf{1 4}$ & $\mathbf{1 5}$ & $\mathbf{1 6}$ & $\mathbf{1 7}$ & $\mathbf{1 8}$ & $\mathbf{1 9}$ & $\mathbf{2 0}$ \\
\hline Number of transfusions & 6 & 6 & 7 & 6 & 6 & 6 & $\mathbf{8}$ & $\mathbf{6}$ & 6 & 7 & 6 & 6 & 6 & 8 & 6 & 6 & 8 & 6 & 6 & 7 \\
Massive hemorrhages & 0 & 0 & 1 & 0 & 0 & 0 & 1 & 0 & 0 & 0 & 0 & 0 & 0 & 1 & 0 & 0 & 1 & 0 & 0 & 0 \\
Mucosal hemorrhages & 0 & 0 & 1 & 0 & 0 & 0 & 0 & 0 & 0 & 1 & 0 & 0 & 0 & 0 & 0 & 0 & 0 & 0 & 0 & 1 \\
Number of infections & 0 & 0 & 0 & 0 & 0 & 0 & 0 & 0 & 0 & 0 & 0 & 0 & 0 & 0 & 0 & 0 & 0 & 0 & 0 & 0 \\
\hline
\end{tabular}

harvested were sent to a dry PC bag, withdrawn by a syringe, and counted with the XE-2100 analyzer. The contents of the separation chamber were then driven into the standard PC bag, to avoid plasma contamination, and then into a PC bag containing additive storage solution (T-SOL; Baxter, Deerfield, IL). After collection, both plasma PC and PC with T-SOL were left undisturbed for 1 hour. For sampling, the plasma PC was connected to a $100 \mathrm{~mL}$ transfer bag using a sterile connection system and approximately $15 \mathrm{~mL}$ was withdrawn for analysis. The other bag contained a mean of $3.0( \pm 0.2) \times 10^{11}$ PLTs, and was preserved in T-SOL at $23^{\circ} \mathrm{C}$ for no longer than 2 days to avoid changes of numbers over time. ${ }^{11}$ The PCs were leukodepleted by MachoPharma filters (Mouvaux, France) to avoid immunologically mediated effects, further possible bacterial contaminations, and infectious disease transmission (cytomegalovirus, human T-lymphotrophic virus Type I and II). ${ }^{12-14}$ Finally, they were also treated by a gamma irradiator for 6 minutes, at the time of transfusion. ${ }^{16,17}$ The treatment and checking of the two groups were similar. Physicians and patients understood and approved the treatment with IPF. The data were analyzed using a nonparametric statistical test and the Mann-Whitney test in order to overcome the underlying assumption of normality in parametrics tests with small sample and because the two samples under consideration may not necessarily have the same number of observations. The conditions of the patients were stabilized about the main parameters (stable $\mathrm{Hb}$; normal coagulation tests; general satisfactory health without fever, cough or infections).

\section{Results}

In this report only the first two categories, PLT count $<10,000 / \mu \mathrm{L}$ (prophylactic therapy) and PLT count $<50,000$ (mucosal hemorrhage), were evaluated, for a total number of 40 patients. Twenty received transfusions of $3.0 \times 10^{11}$ PLTs with a low IPF level $(0 \%-1 \%$ of total infused PLTs $)$ and the other 20 received IPF-rich transfusions ( $3 \%-9 \%$ of total infused PLTs). The dose of infused IPF was different, in accordance with the patient's weight: $3.0( \pm 0.2)$ for children of $40-60 \mathrm{~kg} ; 1.5( \pm 0.2)$ for children of 20-39 $\mathrm{kg}$ (Table 1). In this second case, the remaining half dose of IPF was used to prepare heterologous PLT gel to cure skin ulcers, sores, and bone degeneration in other patients.

The data show that the efficacy of transfusion in the 20 patients who received rich IPF was higher than that of low IPF transfusion (Tables 2 and 3). There was only one case of massive blood loss post-transplantation versus three in the low IPF group and no cases of mucosal hemorrhage. The number of transfusions was lower for patients receiving rich IPF than low IPF solutions and the rich IPF decreased the need for prophylactic transfusions from three to two per week (Figure 1). The timing of engraftment and patient outcome were the same (mean of 10 days \pm 3 ) for patients
A

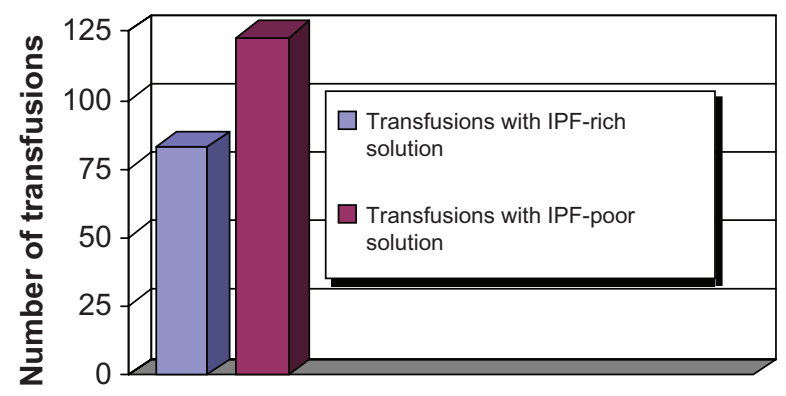

B

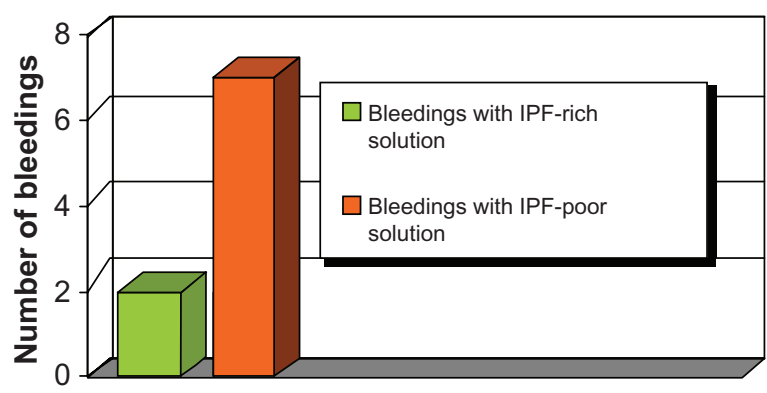

Figure I (A) Use of IPF during post stem cells transplant period. (B) Massive or mucosal hemorrhagic complications during post stem cells transplant period. Abbreviation: IPF, immature platelet fraction. 
Table 4 Mean of the number of transfusions in the two groups of stem cell transplantations (hematological pathologies: 14 acute lymphoblastic leukemia, twelve acute myelocytic leukemia, four non-Hodgkin's lymphoma, two Hodgkin's lymphoma, eight solid tumors)

\begin{tabular}{lllllll}
\hline Group & Mean & N & SD & Median & Minimum & Maximum \\
\hline Poor IPF & 6.45 & 20 & 0.759 & 6 & 6 & 8 \\
Rich IPF & 4.15 & 20 & 0.489 & 4 & 4 & 6 \\
Total & 5.30 & 40 & 1324 & 6 & 4 & 8 \\
\hline
\end{tabular}

Note: The Mann-Whitney test shows a significant difference $(P<0.001)$.

Abbreviation: IPF, immature platelet fraction.

receiving autograft transplants, and there were no cases of hemorrhage, bacterial contamination due to management and counting of IPF, transfusion-transmitted infections, or other health-related complications. ${ }^{18-23}$ We used the MannWhitney test to compare the number of transfusions between the two groups of patients and pathologies (because it is a nonparametric statistical test), and a significant difference was observed (Table 4). The initial health conditions before transplantation were similar, including stable hemoglobin values, normal coagulation tests, and general satisfactory health.

\section{Conclusion}

The exclusion and inclusion criteria of the study excluded only three cases (fever and cough) and one IPF transfusion (PLT clumps in the bag), as European Bone Marrow Transplantation criteria prescribe for a trial. ${ }^{34}$ The processing time to control IPF dosage was relatively short (5 minutes) and did not affect the cost of the procedure. This counting is essential during the last cycle of PLT apheresis, to determine whether the collected plasma has a high percentage of reticulated PLTs for clinical use; if it does not, another cycle is programmed. No viral or bacterial infections due to donors, management of transfusions, or IPF dosage were observed. ${ }^{24,25}$

In our experience it seems beneficial to use IPF-enriched solutions to transfuse children with complex pathologies, such as during PBSC transplantation, and the IPF transfusions are essential for reducing the incidence of hemorrhagic complications. It is necessary to select blood donors with a high percentage of IPF (3.6\%-7.0\% of total PLT).

IPF transfusion needs further investigation to establish the social and economic cost, but the benefits of using IPF solutions include reduction in the severity of hematologic disease and related complications, such as intravascular coagulation during PBSC transplantation in children and young patients, and the frequency of minor side effects including mucosal hemorrhage. ${ }^{26-29}$ The higher cost to carry out "dedicated"
PLT apheresis and the purchase of a modern hemocytometer for quantifying the IPF, is offset by the savings in health and medical support for post-transplantation complications. Laboratory and clinical investigations of the functionality of reticulated PLTs in hemostasis, compared to mature PLTs, encouraged these studies. ${ }^{30-32}$

It is critical also to choose the dosage and the use of IPF as a prophylactic approach to lower the chances of posttransplantation bleeding, especially in high-risk cases. To collect and determine the dosage of the IPF by PLT apheresis, a standardized procedure is essential. The next step in the refinement of this methodology is the integrated output, which comprises a value that indicates the blood volume of selected donors that must be processed to obtain the desired PLT number and IPF. It involves the creation of a registry of "dedicated" donors.

\section{Disclosure}

The authors report no conflicts of interest in this work.

\section{References}

1. Abe Y, Wada H, Tomatsu H, et al. A simple technique to determine thrombopoiesis level using immature platelet fraction (IPF). Thromb Res. 2006;118(4):463-469.

2. Briggs C, Kunka S, Hart D, Oguni S, Machin SJ. Assessment of an immature platelet fraction (IPF) in peripheral thrombocytopenia. Br J Haematol. 2004;126(1):93-99.

3. Kicler TS, Oguni S, Borowitz MJ. A clinical evaluation of high fluorescent platelet fraction percentage in thrombocytopenia. Cytometry. 2006;125(2):282-287.

4. Briggs C, Hart D, Kunka S, Oguni S, Machin SJ. Immature platelet fraction measurement: a future guide to platelet transfusion requirement after haematopoietic stem cells transplantation. Transfus Med. 2006;16(2):101-109.

5. Zucker ML, Murphy CA, Rachel JM, et al. Immature platelet fraction as a predictor of platelet recovery following hematopoietic progenitor cell transplantation. Lab Hematol. 2006;12(3):125-130.

6. Cremer M, Paetzold J, Schlamlish G, et al. Immature platelet fractions as novel laboratory predicting the course of neonatal thrombocytopenia. Br J Haematol. 2008;144(4):613-624.

7. Cesari F, Marcucci R, Caporale R, et al. Relationship between high platelet turnover and platelet function on high risk patients with coronary artery disease on dual antiplatelet therapy. Thromb Haemost. 2008;99(5):930-937.

8. Dreier J, Stormer M, Pichl L, et al. Screening of platelet concentrates: questioning the optimal test strategy. Vox Sang. 2008;95(3):181-188.

9. Hillyer CD, Josephson CD, Blajchman MA, Vostal JG, Epstein JS, Goodman JL. Bacterial contamination of blood components: risks, strategies, and regulation: joint ASH and AABB educational session in transfusion medicine. Hematol Am Soc Hematol Educ Program. 2003:575-589.

10. Albanyan A, Murphy MF, Wilcox M, Harrison P. Changes in the immature platelet fraction within ageing platelet concentrates. J Thromb Haemost. 2008;6(12):2213-2215.

11. Apelseth TO, Bruserud O, Wentzel-Larsen T, Bakken AM, Bjorsvik S, Hervig T. In vitro evaluation of metabolic changes and residual platelet responsiveness in photochemical treated and gamma-irradiated singledonor platelet concentrates during long-term storage. Transfusion. 2007;47(4):653-665. 
12. Sharma RR, Marwaha N. Leukoreduced blood components: advantages and strategies for its implementation. Asian J Transfus Sci. 2010;4(1):3-8.

13. Bowden RA, Slichter JD, Sayers M, et al. A comparison of filtered leukocyte-reduced and cytomegalovirus (CMV) seronegative blood products for the prevention of transfusion associated CMV infection after marrow transplant. Blood. 1995;86(9):3598-3603.

14. Janetzko K, Schlenke P, Klüter $H$. The flow rate significantly influences the leukocyte depletion rate during prestorage in-line filtration of platelet concentrates. Transfus Sci. 1999;21(2):123-128.

15. Heddle NM, Klama L, Kelton JG, et al. Investigations of two interventions to prevent acute reactions to platelets (abstr). Proceedings of the 24th Congress of the ISBT. Mukuhari Japan, 27, 1996.

16. Mintz PD, Wehrli G. Irradiation eradication and pathogen reduction. Ceasing cesium irradiation of blood products. Bone Marrow Transplant. 2009;44(4):205-211.

17. Apelseth TO, Hervig TA, Wentzel-Larsen T, Bruserud O. Cytokine accumulation in photochemically treated and gamma-irradiated platelet concentrates during storage. Transfusion. 2006;46(5):800-810.

18. Picker SM, Oustianskaia L, Schneider V, Gathof BS. Functional characteristics of apheresis-derived platelets treated with ultraviolet light combined with either amotosalen- $\mathrm{HCl}(\mathrm{S}-59)$ or riboflavin (vitamin $\mathrm{B} 2$ ) for pathogen-reduction. Vox Sang. 2009;97(1):26-33.

19. Picker SM, Schneider V, Gathof BS. Platelet function assessed by shear-induced deposition of split triple-dose apheresis concentrates treated with pathogen reduction technologies. Transfusion. 2009;49(6):1224-1232.

20. Picker SM, Schneider V, Oustianskaia L, Gathof BS. Cell viability during platelet storage in correlation to cellular metabolism after different pathogen reduction technologies. Transfusion. 2009;49(11):2311-2318.

21. Picker SM, Speer R, Gathof BS. Functional characteristics of buffycoat PLTs photochemically treated with amotosalen- $\mathrm{HCl}$ for pathogen inactivation. Transfusion. 2004;44(3):320-329.

22. Solheim BG, Seghatchian J. Pathogen reduction of blood components. Transfus Apher Sci. 2008;39:75-82.

23. van Rhenen D, Gulliksson H, Cazenave JP, et al. Transfusion of pooled buffy coat platelet components prepared with photochemical pathogen inactivation treatment: the euroSPRITE trial. Blood 2003;101(6):2426-2433.
24. Simonsen AC, Johansson PI, Conlan MG, et al. Transfusion of 7-day-old amotosalen photochemically treated buffy-coat platelets to patients with thrombocytopenia: a pilot study. Transfusion. 2006;46(3):424-433.

25. Kerkhoffs JL, van Putten WL, Novotny VM, et al. Clinical effectiveness of leucoreduced, pooled donor platelet concentrates, stored in plasma or additive solution with and without pathogen reduction. Br J Haematol. 2010;150(2):209-217.

26. Ståhle M, Carlsson B, Le Blanc K, Korsgren O, Knutson F. Photochemical pathogen inactivation of human serum enables its large-scale application in clinical cell transplantation. Vox Sang. 2010;98(3 Pt 1):e364-365.

27. Bell CE, Botteman MF, Gao X, et al. Cost-effectiveness of transfusion of platelet components prepared with pathogen inactivation treatment in the United States. Clin Ther. 2003;25(9):2464-2486.

28. Sherril J, Slichter MD, Kaufmann RM, et al. Dose of prophylactic platelet transfusion and prevention of hemorrhage. $N$ Engl J Med. 2010;362(7):600-613.

29. Postma MJ, van Hulst M, De Wolf JT, Bottemna M, Staginnus U. Cost-effectiveness of pathogen inactivation for platelet transfusions in the Netherlands. Transfus Med. 2005;15(5):379-387.

30. Toombs CF, Young CH, Glaspy JA, Varnum BC. Megakaryocyte growth and development factor (MGDF) moderately enhances in-vitro platelet aggregation. Thromb Res. 1995;80(1):23-33.

31. Grove EL, Hvas AM, Kristensen SD. Immature platelets in patients with acute coronary syndromes. Thromb Haemost. 2009;101(1):151-156.

32. Grove EL, Hvas AM, Mortensen SB, Larsen SB, Kristensen SD. Effect of platelet turnover on whole blood platelet aggregation in patients with coronary artery disease. J Thromb Haemost. 2011;9(1):185-191.

33. Setting standards of quality and safety for the collection, testing, processing, storage and distribution of human blood and blood components and amending Directive 2001/83/EC. Directive 2002/98/ EC of the European Parliament. Official Journal of the European Union. 2003. Available from: http://eur-lex.europa.eu/LexUriServ/ LexUriServ.do?uri=OJ:L:2003:033:0030:0040:EN:PDF. Accessed January 17, 2012.

34. Gratwohl A, Baldomero H, Frauendorfer K, et al; Joint Accreditation Committee of the International Society for Cellular Therapy (ISCT); European Group for Blood and Marrow Transplantation EBMT (JACIE).The EBMT activity survey 2006 on hematopietic stem cell transplantation. Bone Marrow Transplant. 2008;41(8):687-705.
OncoTargets and Therapy

\section{Publish your work in this journal}

OncoTargets and Therapy is an international, peer-reviewed, open access journal focusing on the pathological basis of all cancers, potential targets for therapy and treatment protocols employed to improve the management of cancer patients. The journal also focuses on the impact of management programs and new therapeutic agents and protocols on

\section{Dovepress}

patient perspectives such as quality of life, adherence and satisfaction The manuscript management system is completely online and includes a very quick and fair peer-review system, which is all easy to use. Visit http://www.dovepress.com/testimonials.php to read real quotes from published authors. 